\title{
RECURRENT REPRESENTATION \\ FOR NON-STATIONARY PARAMETER ESTIMATE OF LEAST SQUARES METHOD \\ WITH LEAST DEVIATIONS FROM 'ATTRACTION' POINTS FOR BILINEAR DYNAMIC SYSTEMS
}

\section{Alexander S. Slabospitsky}

Faculty of Computer Science and Cybernetics, Taras Shevchenko National University of Kyiv, Kyiv, Ukraine, E-mail: sl@univ.kiev.ua

\section{РЕКУРЕНТНЕ ПРЕДСТАВЛЕННЯ \\ ДЛЯ ОЦІНКИ НЕСТАЦІОНАРНИХ ПАРАМЕТРІВ МЕТОДУ НАЙМЕНШИХ КВАДРАТІВ \\ З НАЙМЕНШИМИ ВІДХИЛЕННЯМИ ВІД ТОЧОК "ТЯЖКННЯ" ДЛЯ БІЛІНІЙНИХ ДИНАМІЧНИХ СИСТЕМ}

\section{О. С. СЛАБОСПИЦЬКИЙ}

Факультет комп'ютерних наук та кібернетики, Київський національний університет імені Тараса Шевченка, Київ, Україна, E-mail: sl@univ.kiev.ua

ABSTRACT. The estimation problem of non-stationary parameter matrices is considered for bilinear discrete dynamic system in the case when for these unknown parameter matrices their 'attraction' points are known at any moment. Explicit and recurrent forms of representation are obtained for these parameter estimates of the least squares method with variable forgetting factor and least deviation norm from 'attraction' points under non-classical assumptions. The recurrent algorithm is also proposed for corresponding weighted residual sum of squares.

KEYWORDS: non-stationary parameter estimation, least squares method, 'attraction' points, variable forgetting factor, pseudo-inverse operator, recurrent algorithm, bilinear discrete dynamic system, weighted residual sum of squares.

Резюме. Розглядається задача оцінювання нестаціонарних матриць параметрів для білінійної дискретної динамічної системи у випадку, коли для цих невідомих матриць параметрів їх точки "тяжіння" відомі у кожен момент. Отримані явна та рекурентна форми представлення для цих оцінок параметрів методу найменших квадратів зі змінним фактором забування та найменшою нормою відхилення від точок "тяжіння" при некласичних припущеннях. Запропоновано також рекурентний алгоритм для відповідної зваженої залишкової суми квадратів. 
Ключові СловА: оцінювання нестаціонарних параметрів, метод найменших квадратів, точки “тяжіння", змінний фактор забування, оператор псевдообернення, рекурентний алгоритм, білінійна дискретна динамічна система, зважена залишкова сума квадратів.

\section{ВСТУП}

При розробці складного технічного об'єкта наявність для нього високоякісної математичної моделі завжди є запорукою його успішного впровадження. Використання при цьому параметричної моделі приводить до необхідності розв'язання задачі пошуку оптимальних у деякому розумінні оцінок невідомих параметрів цієї моделі. В залежності від доступного об'єму апріорної інформації про невизначеності системи пропонується скористатися відповідним методом ідентифікації параметрів об'єкта $[1,2]$. На практиці досить часто звертаються до відомого методу найменших квадратів (MHK) [3].

Ситуація, коли можуть бути не справедливі класичні припущення, які забезпечують єдиність оцінки МНК, потребує більш детального дослідження. Його важко провести без використання оператора псевдообернення за Муром-Пенроузом $[4,5]$. Для цього випадку оцінка MHК з найменшою нормою для стаціонарних параметрів регресійної моделі була проаналізована у роботі [6]. В ній для цієї оцінки та відповідної залишкової суми квадратів були отримані рекурентні алгоритми. Потім у публікаціях $[7,8]$ останні результати були перенесені на випадок оцінювання нестаціонарних параметрів регресійної моделі завдяки використанню МНK зі змінним фактором забування.

Врахування додаткової інформації у вигляді знання точок "тяжіння" для невідомих параметрів системи у розглянутому некласичному випадку вносить свої корективи у відповідну оцінку МНК. А саме замість оцінки МНК з найменшою нормою було запропоновано використовувати оцінку МНК з найменшою нормою відхилення від відповідної точки “тяжіння" у кожен момент часу. Якраз для такої оцінки стаціонарних параметрів регресійної моделі та відповідної залишкової суми квадратів у роботі [9] були отримані потрібні рекурентні процедури. Згодом останні результати були перенесені на задачу оцінювання нестаціонарних параметрів регресійної моделі вже за допомогою MHK зі змінним фактором забування [10, 11]. Узагальнення попередніх результатів на клас лінійних дискретних динамічних систем було зроблено у публікаціях $[12,13]$.

Дана робота присвячена поширенню останніх результатів на випадок оцінювання матриць нестаціонарних параметрів білінійних дискретних динамічних систем за допомогою методу найменших квадратів зі змінним фактором забування та найменшою нормою відхилення від заданих точок "тяжіння" у кожен момент часу. 


\section{1. ПОСТАНОВКА ЗАДАЧІ}

Розглянемо задачу оцінювання матриць невідомих параметрів $A, B_{1}, B_{2}, \ldots, B_{m}, B$ для білінійної дискретної динамічної системи

$$
x(k+1)=A x(k)+\sum_{i=1}^{m} u_{i}(k) B_{i} x(k)+B u(k)+\xi(k), \quad k \in \mathbb{N},
$$

де $x(k), \xi(k)-n$-вимірні вектори фазового стану та похибок моделі відповідно, $u(k)=\left(u_{1}(k), u_{2}(k), \ldots, u_{m}(k)\right)^{T}$ - вектор керувань, $x(k), u(k)-$ відомі, $\mathbb{N}$ - множина натуральних чисел.

Припустимо, що блочна матриця невідомих параметрів

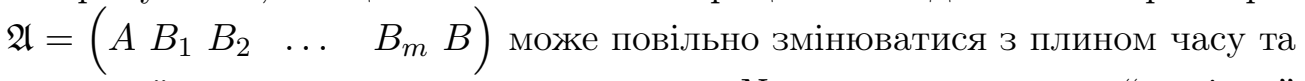
для неї у кожен момент часу $N$ задана точка "тяжіння" $\mathfrak{A}_{*}(N)=\left(A_{*}(N) B_{1 *}(N) B_{2 *}(N) \quad \ldots \quad B_{m *}(N) B_{*}(N)\right), N=0,1,2, \ldots$, де $\quad A_{*}(N), B_{1 *}(N), B_{2 *}(N), \ldots \quad, B_{m *}(N) \in M_{n}(\mathbb{R}), B_{*}(N) \in M_{n, m}(\mathbb{R})$, $M_{n}(\mathbb{R}), M_{n, m}(\mathbb{R})$ - множини квадратних порядку $n$ та розмірності $n \times m$ матриць з дійсними елементами відповідно.

Введемо позначення

$$
Q(\mathfrak{A}, N)=\sum_{k=1}^{N} w(k, N)\|\xi(k)\|^{2},
$$

де $\|\cdot\|$ - евклідова норма,

$$
w(k, N)=\left[\begin{array}{rl}
\prod_{i=k}^{N-1} \lambda(i), & \text { якщо } k=\overline{1, N-1}, \\
1, & \text { якщо } k=N,
\end{array}\right.
$$

$\lambda(i)$ - заданий фактор забування $(\lambda(i) \in(0,1], i \in \mathbb{N})$.

Множина усіх оцінок матриці параметрів $\mathfrak{A}$ методу найменших квадратів зі змінним фактором забування $\{\lambda(k)\}_{k=1}^{\infty}$ у припущенні можливого порушення класичних припущень, що забезпечують її єдиність, знаходиться як розв'язок задачі

$$
\operatorname{Arg} \min _{\mathfrak{A}} Q(\mathfrak{A}, N)
$$

В якості єдиної оцінки на множині оцінок (3) потрібно знайти оцінку $\hat{\mathfrak{A}}(N)=\left(\hat{A}(N) \hat{B_{1}}(N) \hat{B_{2}}(N) \ldots \quad \hat{B_{m}}(N) \hat{B}(N)\right)$ з найменшою нормою відхилення від матриці "тяжіння" $\mathfrak{A}_{*}(N)$ у кожен момент часу $N$. Для оцінки матриці параметрів $\hat{\mathfrak{A}}(N)$ та відповідної зваженої залишкової суми квадратів $q(N)=Q(\hat{\mathfrak{A}}(N), N)$ також необхідно розробити рекурентні алгоритми, які стануть у нагоді при обробці інформації у режимі реального часу.

\section{2. ОТРИМАННЯ ЯВНОЇ ФОРМИ ПРЕДСТАВЛЕННЯ ОЦНКИ}

Перш ніж переходити до побудови рекурентних алгоритмів оцінювання, спочатку потрібно навести вигляд оцінки $\hat{\mathfrak{A}}(N)$ для білінійного дискретного 
динамічного об'єкта. Ï̈̈ явну форму представлення надає нижченаведене твердження.

Теорема 1. Очінка $\hat{\mathfrak{A}}(N)$ методу найменших квадратів зі змінним фактором забування $\{\lambda(k)\}_{k=1}^{\infty}$ та з найменшою нормою відхилення від заданої точки "тлжіння" $\mathfrak{A}_{*}(N)$ у кожен момент часу $N$ для білінійної дискретної динамічної системи (1) при некласичних припущеннях, що не гарантують единість оиінки, мае вигляд:

$$
\hat{\mathfrak{A}}(N)=\left[\tilde{Z}_{N}^{+} \tilde{X}_{2, N+1}\right]^{T}+\mathfrak{A}_{*}(N)\left[E_{n+n m+m}-\tilde{Z}_{N}^{+} \tilde{Z}_{N}\right], \quad N \in \mathbb{N},
$$

де $\left(^{+}\right)$- символ псевдообернення за Муром-Пенроузом, $E_{n}-$ одинична матриия порядку $n$,

$$
\begin{gathered}
\tilde{X}_{2, N+1}=\left(\begin{array}{c}
w^{\frac{1}{2}}(1, N) x^{T}(2) \\
w^{\frac{1}{2}}(2, N) x^{T}(3) \\
\vdots \\
w^{\frac{1}{2}}(N, N) x^{T}(N+1)
\end{array}\right), \\
\tilde{Z}_{N}=\left(\begin{array}{c}
w^{\frac{1}{2}}(1, N) z^{T}(1) \\
w^{\frac{1}{2}}(2, N) z^{T}(2) \\
\vdots \\
w^{\frac{1}{2}}(N, N) z^{T}(N)
\end{array}\right), z(k)=\left(\begin{array}{c}
x(k) \\
u(k) \otimes x(k) \\
u(k)
\end{array}\right),
\end{gathered}
$$

$\otimes$ - операція тензорного добутку.

Доведення. Помножимо $k$-те рівняння системи співвідношень (1) на $w^{\frac{1}{2}}(k, N), k \in \mathbb{N}$. Це дозволяє представити систему перших $N$ таких рівнянь у наступному вигляді:

$$
\tilde{X}_{2, N+1}^{T}=\mathfrak{A} \tilde{Z}_{N}^{T}+\tilde{\Xi}_{N}^{T}, \quad N \in \mathbb{N},
$$

де

$$
\tilde{\Xi}_{N}=\left(\begin{array}{c}
w^{\frac{1}{2}}(1, N) \xi^{T}(1) \\
w^{\frac{1}{2}}(2, N) \xi^{T}(2) \\
\vdots \\
w^{\frac{1}{2}}(N, N) \xi^{T}(N)
\end{array}\right)
$$

А так як має місце

$$
\operatorname{Arg} \min _{\mathfrak{A}} Q(\mathfrak{A}, N)=\operatorname{Arg} \min _{\mathfrak{A}}\left\|\tilde{\Xi}_{N}\right\|^{2},
$$

то на цій множині оцінок потрібна оцінка $\hat{\mathfrak{A}}(N)$ згідно роботи [13] набуває форми

$$
\hat{\mathfrak{A}}(N)=\left[\tilde{Z}_{N}^{+} \tilde{X}_{2, N+1}\right]^{T}+\mathfrak{A}_{*}(N)\left[E_{n+n m+m}-\tilde{Z}_{N}^{+} \tilde{Z}_{N}\right], \quad N \in \mathbb{N} .
$$

Доведення завершено. 


\section{3. ПОБУДОВА РЕКУРЕНТНОГО АЛГОРИТМУ ОЦННЮВАННЯ}

При обробці спостережень у режимі реального часу виникає потреба у наявності можливості рекурентного перерахунку оцінок невідомих параметрів. Звернемося до побудови рекуренту для оцінки $\hat{\mathfrak{A}}(N)$ матриці невідомих параметрів $\mathfrak{A}$ об'єкта (1).

Теорема 2. Рекурентний алгоритм для оиінки (4) матриці невідомих параметрів $\mathfrak{A}$ методу найменших квадратів зі змінним фактором забування $\{\lambda(k)\}_{k=1}^{\infty}$ та найменшою нормою відхилення від заданої точки "тяжіння" $\mathfrak{A}_{*}(N)$ у кожен момент часу $N$ для білінійної дискретної динамічної системи (1) при некласичних припущеннях, що не гарантують єдиність оцінки, набувае такого вигляду:

якщо $\delta(N+1)>0$, mо

$$
\left\{\begin{aligned}
\hat{\mathfrak{A}}(N+1) & =\hat{\mathfrak{A}}(N)+ \\
& +\frac{1}{\delta(N+1)}[x(N+2)-\hat{\mathfrak{A}}(N) z(N+1)] z^{T}(N+1) P(N)+ \\
& +\left[\mathfrak{A}_{*}(N+1)-\mathfrak{A}_{*}(N)\right] \times \\
& \times\left[P(N)-\frac{1}{\delta(N+1)} P(N) z(N+1) z^{T}(N+1) P(N)\right], \\
R(N+1) & =\frac{1}{\lambda(N)}\{R(N)- \\
& -\frac{1}{\delta(N+1)}\left[R(N) z(N+1) z^{T}(N+1) P(N)+\right. \\
& \left.+P(N) z(N+1) z^{T}(N+1) R(N)\right]+ \\
& \left.+\frac{\gamma(N+1)}{\delta^{2}(N+1)} P(N) z(N+1) z^{T}(N+1) P(N)\right\}, \\
P(N+1) & =P(N)-\frac{1}{\delta(N+1)} P(N) z(N+1) z^{T}(N+1) P(N),
\end{aligned}\right.
$$

а у протилежному випадку

$$
\left\{\begin{aligned}
\hat{\mathfrak{A}}(N+1) & =\hat{\mathfrak{A}}(N)+ \\
& +\frac{1}{\gamma(N+1)}[x(N+2)-\hat{\mathfrak{A}}(N) z(N+1)] z^{T}(N+1) R(N)+ \\
& +\left[\mathfrak{A}_{*}(N+1)-\mathfrak{A}_{*}(N)\right] P(N) \\
R(N+1) & =\frac{1}{\lambda(N)}\{R(N)- \\
& \left.-\frac{1}{\gamma(N+1)} R(N) z(N+1) z^{T}(N+1) R(N)\right\} \\
P(N+1) & =P(N)
\end{aligned}\right.
$$


з початковими умовами

$$
\hat{\mathfrak{A}}(0)=\mathfrak{A}_{*}(0), R(0)=\Theta_{n+n m+m}, P(0)=E_{n+n m+m},
$$

де $\Theta_{n}-$ нулъова матрииял порядку $n, \delta(N+1)=z^{T}(N+1) P(N) z(N+1)$, $\gamma(N+1)=\lambda(N)+z^{T}(N+1) R(N) z(N+1)$.

Доведення. При побудові рекурентного співвідношення для оцінки (4) потрібно прийняти до уваги явну форму представлення цієї оцінки, яка була отримана у попередній теоремі. Далі необхідно врахувати структуру білінійної дискретної динамічної системи та застосувати до оцінки (4) результат конструювання рекурентної процедури з роботи [13].

У підсумку одержуємо потрібний рекурентний алгоритм (5-6) для оцінки (4) блочної матриці невідомих параметрів $\mathfrak{A}=\left(\begin{array}{llll}A B_{1} B_{2} & \ldots & B_{m} B\end{array}\right)$, яка може повільно змінюватися з плином часу.

Для контролю якості процесу оцінювання нестаціонарних параметрів білінійного об'єкта в режимі реального часу корисною буде наявність рекурентної процедури для перерахунку відповідної зваженої залишкової суми квадратів.

Теорема 3. Рекурентний алгоритм для зваженої залишкової суми квадратів $q(N)=Q(\hat{\mathfrak{A}}(N), N)$ для білінійної динамічної системи (1) з функиіоналом якості (2) мае вигляд:

$$
\begin{aligned}
& q(N+1)=\left[\begin{array}{c}
\lambda(N) q(N), \text { якщо } \delta(N+1)>0, \\
\lambda(N)\left\{q(N)+\frac{1}{\gamma(N+1)}\|x(N+2)-\hat{\mathfrak{A}}(N) z(N+1)\|^{2}\right\}, \\
y \text { протилежсном випадку }
\end{array}\right. \\
& \text { з початковою умовоюо } q(0)=0 .
\end{aligned}
$$

Доведення. Для отримання потрібної рекурентної процедури для зваженої залишкової суми квадратів $q(N)=Q(\hat{\mathfrak{A}}(N), N)$ достатньо скористатися відповідним результатом з роботи [13] та застосувати його до оцінки (4) матриць параметрів білінійної дискретної динамічної системи.

В результаті отримаємо потрібний алгоритм (7) для перерахунку значень функціоналу $q(N)$.

\section{Висновки}

Для оцінки матриць нестаціонарних параметрів білінійної дискретної динамічної системи (1) методу найменших квадратів зі змінним фактором забування та з найменшою нормою відхилення від заданої точки "тяжіння" у кожен момент часу при некласичних припущеннях, що не гарантують її єдиність, отримано явну (4) та рекурентну (5-6) форми представлення. Запропоновано рекурентну процедуру (7) для перерахунку відповідної зваженої залишкової суми квадратів. 


\section{ЛiтературА}

1. Eykhoff P. System Identification: Parameter and State Estimation. Chichester, England: Wiley, 1974. 555 p.

2. Ljung L. System Identification: Theory for the User. 2nd ed. Upper Saddle River, NJ : Prentice-Hall, 1999. 609 p.

3. Hsia T. C. System Identification. Least-squares Methods. Toronto : Lexington Books, 1977. $165 \mathrm{p}$.

4. Moore E. H. On the reciprocal of the general algebraic matrix. Bull. American Mathematical Society. 1920. Vol. 26, № 9. P. 394-395.

5. Penrose R. A generalized inverse for matrices. Proc. Cambridge Philoc. Soc. 1955. Vol. 51, № 3. P. 406-413.

6. Albert A. Regression and the Moore-Penrose Pseudoinverse. New York: Academic Press, 1972. 180 p.

7. Слабоспицький О. С. Рекурентний алгоритм оцінювання методом найменших квадратів зі змінним фактором забування при некласичних припущеннях. Вісник Київсъкого університету. Серія: фіз.-мат. науки. 1999. № 4. C. $237-240$.

8. Слабоспицький О. С. Рекурентне оцінювання нестаціонарних параметрів методом найменших квадратів зі змінним фактором забування при некласичних припущеннях. Вісник Київсъкого університету. Серія: фiз.-мат. науки. 2000. № 1. C. 282-285.

9. Слабоспицький О. С. Використання додаткової інформації в рекурентному оцінюванні параметрів систем з дискретним часом методом найменших квадратів при некласичних припущеннях. Вісник Київсъкого університету. Серія: фiз.-мат. науки. 2008. № 4. С. 179-182.

10. Слабоспицький О. С. Оцінювання нестаціонарних параметрів методом найменших квадратів зі змінним фактором забування та мінімальною нормою відхилення від точок "тяжіння" для систем при некласичних припущеннях. Вісник Київсъкого начіонального університету імені Тараса Шевченка. Серія фiз.-мат. науки. 2012. № 4. С. 199-202.

11. Слабоспицький О. С. Рекурентне оцінювання нестаціонарних параметрів систем при некласичних припущеннях методом найменших квадратів зі змінним фактором забування та найменшою нормою відхилення від точок "тяжіння". Журнал обчисл. та прикл. матем. 2012. № 2 (108). С. 59-65.

12. Слабоспицький О. С. Рекурентний алгоритм для оцінювання нестаціонарних параметрів методом найменших квадратів зі змінним фактором забування та найменшими відхиленнями від точок "тяжіння" для лінійних динамічних систем при некласичних припущеннях. Вісник Київсъкого національного університету імені Тараса Шевченка. Серія фіз.-мат. науки. 2016. № 3. С. 106-110.

13. Слабоспицький О. С. Рекурентне оцінювання нестаціонарних параметрів методом найменших квадратів зі змінним фактором забування та найменшою нормою відхилення від точок "тяжіння" для лінійних динамічних систем при некласичних припущеннях. Журнал обчисл. та прикл. матем. 2016. № 3 (123). C. 95-102. 